\title{
Upregulation of Ski in Fibroblast is Implicated in the Peroxisome Proliferator- Activated Receptor $\delta$-Mediated Wound Healing
}

\author{
Jun Li $i^{a}$ Ping Lic Yan Zhang ${ }^{b}$ Gong-Bo Li ${ }^{b}$ Feng-tian He ${ }^{b}$ Yuan-Guo Zhou \\ Kang Yang ${ }^{a}$ Shuang-Shuang Dai \\ aDepartment of Cardiothoracic Surgery, Southwest Hospital, Third Military Medical University, \\ Chongqing; bepartment of Biochemistry and Molecular Biology, Third Military Medical University, \\ Chongqing; ${ }^{c}$ The Molecular Biology Center, State Key Laboratory of Trauma, Burn and Combined Injury, \\ Research Institute of Surgery and Daping Hospital, Third Military Medical University, Chongqing
}

\section{Key Words}

Ski $\cdot \operatorname{PPAR} \delta \cdot$ Fibroblast $•$ Wound healing

\begin{abstract}
Background/Aim: Both peroxisome proliferator-activated receptor (PPAR) $\delta$ and Ski are reported to be involved in skin wound repair. However, their link is unclear. Our aim is to investigate the interaction of PPAR $\delta$ and Ski and this interaction-associated effect in wound healing. Methods: Effect of PPAR $\delta$ activation on Ski expression was detected in rat skin fibroblasts by real-time PCR and western blot. Luciferase assay, electrophoretic mobility shift assay (EMSA) and chromatin immunoprecipitation (ChIP) assay were performed to identify the binding site of PPAR $\delta$ in the promoter region of rat Ski gene. And the functional activity of PPAR $\delta$ regulation to Ski was detected in fibroblast proliferation and rat skin wound healing model. Results: PPAR $\delta$ agonist GW501516 upregulated Ski expression in a dose-dependent manner. Direct repeat-1 (DR1) response element locating at -865 -853 in Ski promoter region was identified to mediate PPAR $\delta$ binding to Ski and associated induction of Ski. Furthermore, PPARS upregulated Ski to promote fibroblasts proliferation and rat skin wound repair, which could be largely blocked by pre-treated with Ski RNA interference. Conclusion: This study demonstrates that Ski is a novel target gene for PPAR $\delta$ and upregulation of Ski to promote fibroblast proliferation is implicated in the PPAR $\delta$-mediated wound healing.
\end{abstract}

Copyright (C) 2012 S. Karger AG, Basel

Shuang-Shuang Dai, M.D.\&Ph D. and Kang Yang, M.D.\&Ph D.
Department of Biochemistry and Molecular Biology, and Department of cardiothoracic surgery, Southwest Hospital,

Third Military Medical University, 30 Gaotanyan, Shapingba, Chongqing 400038 (China)

E-Mail tmmubiodss@yahoo.com.cn or E-Mail kangyang@mail.tmmu.edu.cn 


\section{Introduction}

Acting as a protective shield of body, Skin is subjected to constant aggression and insults that may result in the loss of its integrity and function. Following skin injury, the course of wound healing will be priminged, which includes an overlapping pattern of events such as inflammation, re-epithelialization, generation of granulation tissue and matrix and tissue remodeling [1]. These events are temporally and spatially regulated by a variety of growth factors and cytokines that orchestrate the manifold cellular activities [2].

Ski, a homologue of the pro-oncogenic v-Ski protein, is highly conserved across various species and widely distributed in different tissues [3-5]. As a versatile transcriptional regulator, it modulates multiple gene expression and is involved in many physiological and pathological processes [6-9]. However, the transcriptional or translational modulation of Ski gene in these conditions is not clear. Our recent study has demonstrated that Ski is a new tissue repair-related gene, which is mainly expressed in fibroblasts and modulates wound healing and scar formation by regulating TGF- $\beta$-dependent or -independent pathway [1012]. Accordingly, it is essential to investigate the endogenous or exogenous factors to regulate Ski expression or function, which has the potential to provide a novel strategy to accelerate wound healing via modulating Ski-mediated signaling and effects.

Nuclear receptors are a class of proteins found within cells that are responsible for sensing steroid and thyroid hormones and certain other molecules. In response, these receptors regulate the expression of specific genes, thereby controlling the development, homeostasis, and metabolism of the organism [13-15]. The nuclear receptor PPAR $\delta$ is one identified isoform of peroxisome proliferator-activated receptors (PPARs) [16, 17]. As well as the other two isoforms PPAR $\alpha$ and PPAR $\gamma$, it regulate gene expression by forming heterodimers with the retinoid $\mathrm{X}$ receptor (RXR) via specific recognition sequences termed PPAR response elements (PPRE), which are located in the target genes [18-20]. Recently, multiple evidence have shown that PPAR $\delta$ has the ability to promote wound healing [21-24]. Although multiple factors participate in the execution of PPAR $\delta$ action, its effector genes that it regulates in wound healing remains largely unexplored.

In an attempt to elucidate these issues, we focus on identifying the relationship of Ski and PPAR $\delta$ in fibroblasts. We report that Ski is a novel target gene for PPAR $\delta$. By binding to a functional PPRE localized in the Ski promoter, activation of PPAR $\delta$ upregulates the expressions of Ski mRNA and protein. And this upregulation is implicated in the effect of PPAR $\delta$ on promoting fibroblast proliferation and associated skin wound healing in rats.

\section{Materials and Methods}

Animals and reagents

Specific pathogen-free adult male and female Wistar rats (180-220 g) were purchased from the Animal Centre, Research Institute of Surgery and Daping Hospital, TMMU, Chongqing, China (Certificate No. scxk (Yu) 2002-0002, grade II). pSuper-c-Ski-RNAi was made previously [11], which has been confirmed to successfully knockdown Ski expression both in rat fibroblasts and wound tissues in our recent study [10, 11]. Antibodies specific to Ski (sc-9140), PPAR $\delta$ (sc-7197), $\beta$-actin (sc-1616), PPAR $\delta$ agonist GW501516 (sc-202642) and antagonist GSK0660 (sc-203985) were purchased from Santa Cruz Biotechnology (Santa Cruz, CA, USA).

\section{Primary fibroblasts culture and treatments}

Primary fibroblasts were obtained from back skin of 4-6-week-old Wistar rats. Fibroblast culture was established as described previously $[11,25]$. Briefly, fibroblasts were incubated at $5 \% \mathrm{CO}_{2}$ in a humidified $37^{\circ} \mathrm{C}$ incubator, cultured with Dulbecco's minimum essential medium (DMEM) supplemented with $10 \%$ heat-inactivated fetal bovine serum (FBS) three times a week. When cells reached confluence, they were passaged by trypsinization, resuspended and re-plated. Fibroblasts at passage 3-8 were used. These fibroblasts were treated with DMSO or various concentrations of GW501516 (25, 50 and $100 \mathrm{nmol} / \mathrm{L})$ for 
24 hours. To confirm the induction of Ski is mediated by PPAR $\delta$ activation, cells were pre-treated for $3 \mathrm{~h}$

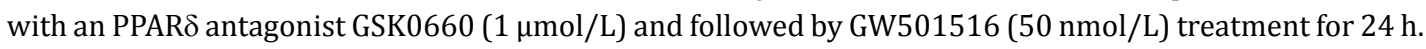

\section{Model of wound healing and treatments}

A model for wound healing in rats was used as previously described [26]. Two $2 \mathrm{~cm}$ diameter, fullthickness circular skin flaps were cut from the buttocks. One wound was treated with medicines, while the other wound was used as an internal control. Injured rats were randomly divided into two groups: (1) one wound (left) was injected with $100 \mu \mathrm{g}$ GW501516, and the internal control side (right) was injected with vechical (DMSO); (2) the left wound was pre-injected $100 \mu \mathrm{g}$ pSuper-c-Ski-RNAi (which has been reported to successfully knock down of Ski in vivo in our recent study [10] and 6 hours later followed with $100 \mu \mathrm{g}$ GW501516 treatment, while the right wound was injected with DMSO. These medicines were administrated to animals immediately after wounding firstly and then injected weekly. On day $0,6,12$ and 18 postwounding, the expression of Ski mRNA and protein, wound closure and histopathological analysis were determined and observed. At least six animals were used in each detection or assay.

\section{Real-time PCR and western blot assays}

Total RNA was isolated from all samples using TRIzol (Invitrogen, Carlsbad, CA, USA) according to the manufacturer's instructions, and total protein was extracted using M-PERTM protein extraction reagent (Pierce, Rockford, IL, USA). Quantitative polymerase chain reaction (qPCR) amplification was performed in triplicate, using the SYBR Green PCR reagent system. Primers for Ski: sense, 5'-TCA ACT CGG TGT GCG ATG3', and antisense,5'-CGT CCG TCT TGG TGA TGA G-3'; and for glyceraldehyde-3-Phosphatedehydro-genase (GAPDH): sense, 5'-AGG TTG TCT CCT GCG ACT T-CA-3', and antisense, 5'-TGG TCC AGG GTT TCT TAC TCC3'. Real-time PCR was carried out as follows: initial denaturation for $5 \mathrm{~min}$ at $94^{\circ} \mathrm{C}$ and 40 cycles of PCR consisting of $15 \mathrm{~s}$ at $94^{\circ} \mathrm{C}, 15 \mathrm{~s}$ at $59^{\circ} \mathrm{C}$ and $20 \mathrm{~s}$ at $72^{\circ} \mathrm{C}$. Quantifications were always normalized using endogenous control GAPDH.

For western blot assay, whole-cell lysates of cultured fibroblasts or wound tissues of rat wound healing model were collected with M-PERTM protein extraction reagent (Pierce) containing protease inhibitormixture (Calbiochem) to detect Ski expression. Equal amounts of protein were separated by SDS/ PAGE (10\% gels) and transferred on to an Immobilon-P PVDF membrane (Millipore). The expression of $\beta$ actin in each sample was also detected to show equal protein loading.

Plasmid construction and site-directed mutagenesis

Rat Ski promoter region containing fragment $(-2277 \sim-19)$ was amplified by PCR with the oligonucleotides 5'-CGG GGT ACC GAT TTG GCT GTC CCT TC-3' (forward primer) and 5'-CCG CTC GAG TCC TTT GAC CCT CTA CC -3' (reverse primer) using fibroblasts-derived genomic DNA as template. The fragment was cloned into pGL3-basic vector after digestion with Kpn I and Xhol, and the resulting plasmid was named as pGL3-Ski. The deletion mutants of this luciferase reporter vector were amplified and these forward primers are as followed: (1) pGL3-Ski ${ }_{-1178 \sim-19}$ : 5 '-CGG GGT ACC CCT GTC CTT TGC TTT TGG AGT TTC-3'; (2) pGL3-Ski ${ }_{-1103 \sim-19}$ : 5'-CGG GGT ACC CAG GAA CAA AAC TCC CGC AGA -3'; (3) pGL3-Ski ${ }_{-958 \sim-19}$ : 5'- CGG GGT ACC AGA GTA GCC TGC CTA GTC CAG G-3';(4) pGL3-Ski ${ }_{-851 \sim-19}$ : 5'- CGG GGT ACC TAG AAG GTA CAG GCT TAT CAC AAT G-3'; (5) pGL3-Ski ${ }_{-762 \sim-19}$ : 5'-CGG GGT ACC GGG TGG GTG GAT AGA TGA TAG AT-3'; (6) pGL3-Ski ${ }_{-470 \sim 19}$ : 5'- CGG GGTA CCG GAG GGG CAG CTG TGT CCA TA -3'; (7) pGL3-Ski ${ }_{-331 \sim 19}$ : 5'- CGG GGT ACC AGA CCC TTG TGG AAG CCC TG-3'. Their reverse primers are similar to pGL3-Ski as described above. In addition, a nucleotide substitution was introduced into the DR1 site (-865 - 853) in the Ski promoter using the QuikChange site-directed mutagenesis kit (Stratagene, CA). PCR amplification of the wild-type rat pGL3Ski luciferase reporter plasmid was performed using site-directed mutation primers: 5'-GGG ATA GTC TTA AGG CGA GTA GAC ATG TAG AAG GTA CAG GC-3' (forward) and 5'-GCC TGT ACC TTC TAC ATG TCT ACT CGC CTT AAG ACTA TCC C-3' (reverse).

\section{Luciferase assay}

Fibroblasts, grown to $80-90 \%$ confluence in 48 -well plates, were transiently transfected using Lipofectamine 2000 with luciferase reporter pGL3-Ski and its mutants respectively. Five hours after transfection, fresh complete medium was added and the cells were incubated for another $4 \mathrm{~h}$. Then the cells were treated with GW501516 (50 nmol/L), or GSK0660 (1 $\mu \mathrm{mol} / \mathrm{L})$ followed by GW501516 (50 nmol/L), or 
vehicle ( $0.1 \%$ DMSO) alone for $24 \mathrm{~h}$. Transfection efficiency was monitored by cotransfection of pCMV- $\beta$ gal plasmid. Cell extracts were prepared, and the luciferase and $\beta$-galactosidase assays were performed using the corresponding assay system according to the manufacturer's instructions (Promega, USA). Transfection experiments were performed at least 3 times in triplicate. And the luciferase activity was normalized against $\beta$-galactosidase activity.

Electrophoretic mobility shift assay (EMSA)

EMSA was performed as described previously [27]. In brief, the DNA probe containing a putative PPAR response element (PPRE/DR1,-865 -853) (forward: 5'- CTTAAGGTAAGGGGACATGTA-3', reverse: 5'-TACATGTCCCCTTACCTTAA-G-3') or its mutated consensus sequence (forward: 5'-CTTAAGGCGAGGTAACA TGTA-3', reverse: 5'-TACATACTCCCTTAAAGTAAG-3') was synthesized. It was end-labeled with biotin. The EMSA was performed using the LightShift chemiluminescent EMSA kit (Pierce, Rockford, IL, USA) according to the manufacturer's instructions. Briefly, the labeled probes were incubated with the nuclear extracts from fibroblasts for $20 \mathrm{~min}$ at $25^{\circ} \mathrm{C}$, and then the reaction samples were electrophoresed on a $6 \%$ non-denaturing acrylamide gel in a $0.5 \times$ Tris-borate-EDTA buffer. After transferred to nylon membrane, the biotin-labeled probes were detected. For supershift experiments, anti-PPAR $\delta$ antibody (sc-7197, Santa Cruz, USA) was preincubated for $20 \mathrm{~min}$ in binding buffer prior to the addition of the nuclear extracts as described above.

\section{Chromatin Immunoprecipitation (ChIP) Assay}

ChIP assays were performed using a ChIP assay kit (Upstate Biotechnology, Lake Placid, NY, USA) according to the manufacture's instructions. Briefly, after treatment with $50 \mathrm{nmol} / \mathrm{L}$ GW501516 for $24 \mathrm{~h}$, fibroblasts were cross linked with $1 \%$ formaldehyde, and then disrupted in SDS lysis buffer containing the protein inhibitor cocktail. Chromatin was sonicated to shear DNA to an average length between 200 and $1000 \mathrm{bp}$ as verified by agarose gel. Subsequently, chromatin was immunoprecipitated with anti-PPAR $\delta$ antibody (sc-7197, Santa Cruz, USA), taking rat IgG as negative control. Final DNA extractions were PCR amplified using primer pairs that cover the novel DR1 sequence in the Ski promoter region as follows: forward primer, 5'-TCTGTTTGGCTGGCCTGAGGGA-3'; reverse primer, 5'-AAGATAGATCCCAGACTTTAT-3'.

\section{Proliferation assay of fibroblasts}

Proliferation of fibroblasts was determined by Cell Count Kit-8 (CCK-8 Kit, Beyotime Inst Biotech, China) using WST-8(2-(2-methoxy-4-nitrophenyl)-3-(4-nitrophenyl)-5-(2,4-disulfophenyl)-2H-tetrazolium, monosodium salt) dye method in accordance with the manufacturer's instructions and the references [28, 29]. Briefly, rat skin fibroblasts were synchronized with DMEM $/ 0.4 \% \mathrm{FBS}$ for $24 \mathrm{~h}$ and subsequently treated with GW501516 (50 nmol/L) or DMSO. To investigate whether Ski was implicated in the effect of PPAR $\delta$ activation on fibroblasts proliferation, $200 \mathrm{ng}$ pSuper-Ski-RNAi was transfected into fibroblasts for 6 hours and its effect on Ski protein expression was detected by western blot as previously described, which has been confirmed to efficiently RNAi Ski expression in fibroblasts in our recent study [11], then followed by GW501516 treatment. And $24 \mathrm{~h}, 48 \mathrm{~h}$ and $72 \mathrm{~h}$ after GW501516 or DMSO treatment respectively, the cells were incubated for $4 \mathrm{~h}$ at $37^{\circ} \mathrm{C}$ with WST-8 and the absorbance was finally determined at $450 \mathrm{~nm}$ using a microplate reader.

\section{Observation of wound healing and histopathological analysis}

Wound closure was observed on day 6, day 12 and day 18 post-wounding. And to further investigate the progression of wound repair, histopathological analysis was performed as previously described [10]. Briefly, wounded skin was excised, fixed overnight in $4 \%$ buffered formalin solution and embedded in fibrowax. Tissue sections $(6 \mathrm{~mm})$ were stained with haematoxylin and eosin (H\&E) for morphological assessment.

\section{Statistical analysis}

Comparisons between two groups were made with unpaired Student's t-test. Non-parametric comparisons between three or more groups were made with ANOVA followed by Bonferroni's post hoc test. All data were expressed as means \pm standard deviation (SD). $P<0.05$ was considered statistically significant. 
Fig. 1. PPAR $\delta$ ligand GW501516 induces Ski mRNA and protein expression in fibroblasts. Primary rat skin fibroblasts were incubated for 24 hours with various concentrations of GW501516 or vehicle DMSO (0.1\% DMSO). (A) qRT-PCR for Ski mRNA. (B) Western blot for Ski protein. (C) and (D) The GW501516 (50 nmol/L)mediated increases in Ski expression were significantly inhibited when the cells were pre-treated for $3 \mathrm{~h}$ with an PPAR $\delta$ antagonist GSK0660 (followed by GW501516 treatment for $24 \mathrm{~h}$ ) revealed by qRT-PCR (C) and Western blot (D). Data were mean \pm SD from three experiments in triplicate. ${ }^{*} P<0.05$, when compared to the group with DMSO treatment.

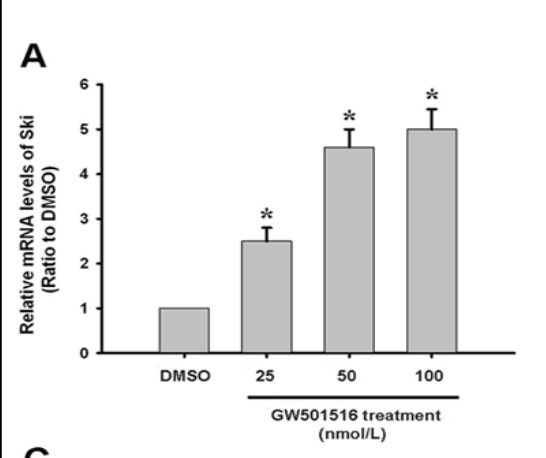

B

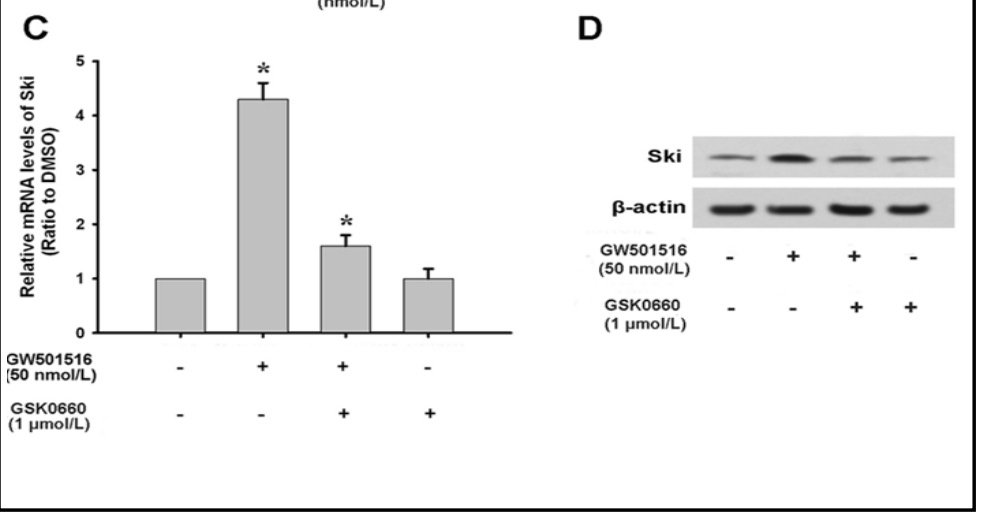

\section{Results}

Treatment with PPAR agonists leads to upregulation of Ski in rat fibroblast cells

When the primary cultured rat fibroblasts were treated with GW501516, a specific ligand of PPAR $\delta$, siginificant increases of Ski mRNA and protein levels were demonstrated in a concentration-dependent manner (Fig. 1A and B). To confirm this regulation of Ski by GW501516 was medicated by its activity to activate PPAR $\delta$, we next investigated the effects of GSK0660, which is an irreversible inhibitor of PPAR $\delta$ and observed a significant reduction in PPAR $\delta$-induced upregulation of Ski (Fig. 1C and D). These data indicate clearly that Ski expression is regulated in a PPAR $\delta$-dependent manner.

PPAR activation enhances transcriptional activation of ski promoter

Upregulation of Ski mRNA by GW501516 suggests that PPAR $\delta$ activation modulates Ski expression at the transcriptional level. We then hypothesized that activation of PPAR $\delta$ enhances Ski expression may be due to exert its stimulatory activity on Ski promoter. To test this hypothesis, we constructed a luciferase reporter plasmid (pGL3-Ski) that was driven by rat Ski promoter region (-2277 -19). Following transfected with pGL3-Ski, rat fibroblasts were treated with PPAR $\delta$ ligand GW501516. As shown in Figure 2, GW501516 administration significantly enhanced the Ski promoter activity, but the increase in promoter activity was substantially attenuated when the cells were pretreated with PPAR $\delta$ selective antagonist GSK0660. These results indicate that activation of PPAR $\delta$ enhances Ski promoter activity. Being exogenous PPAR $\delta$ and retenoid X receptor (RXR) $\alpha$ were not transfected to the cells, these results also suggest that endogenous PPAR $\delta$ in fibroblasts is sufficient to elicit this activity.

PPAR B Binds to the PPRE in the Ski Gene Promoter

To search for PPRE that may mediate Ski induction by PPAR $\delta$ ligand, the rat Ski promoter region (-2277 -19) was subjected to in silico analysis with a Web-based algorithm (NUBIScan) [17]. Combination with analysis of relative references, nine predicted 
Fig. 2. PPAR $\delta$ induces the transcriptional activity of rat Ski gene promoter. Rat Ski gene promoter region (-2277 -19) was cloned into pGL3-basic vector plasmid and transfected into rat skin fibroblasts. The cells were treated with GW501516 (50 nmol/L) or DMSO with or without pre-treatment of GSK0660, PPAR $\delta$ antagonist. The reporter assay was performed at least 3 times in triplicate. The luciferase activity was normalized against $\beta$-galactosidase activity. Data were mean \pm SD and represented as fold induction. ${ }^{*} P<0.05$ between the two groups.

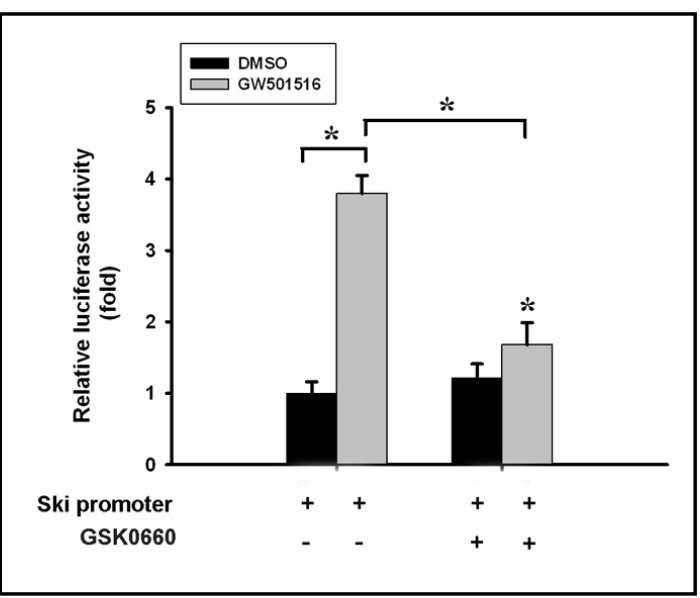

Table 1. On line analysis of putative PPRE in rat Ski promoter region. To analysis potential PPRE in rat Ski promoter region, Prediction was performed with a Web-based algorithm (NUBIScan). Nine putative PPRE sites were predicted in -2277 -19 region of Ski promoter. Their position, strand and sequence were presented.

\begin{tabular}{ccc}
\hline & $\begin{array}{c}\text { Prediction of PPRE in Ski promoter region } \\
\text { (http://www.nubiscan.unibas.ch/) }\end{array}$ \\
Repeat & Position (Strand) & Site Sequence \\
\hline DR1 & $-1264(-)$ & TGGCCAaAGCTCA \\
IR0 & $-1146(-)$ & AGGTGATGGACT \\
ER3 & $-1066(-)$ & TTAACTcagAGGCCA \\
DR1 & $-865(-)$ & AGGTAAgGGGACA \\
DR2 & $-823(-)$ & AGAGCAacAGGACA \\
DR1 & $-816(-)$ & AGGACAtGGGCCT \\
ER1 & $-717(+)$ & TGGCCTaGGGCCA \\
ER6 & $-717(+)$ & TGGCCTagggCCAGCCCA \\
DR1 & $-377(-)$ & AGTGAAaAGGGTA \\
\hline
\end{tabular}

potential PPREs were selected and their sequences and locations were shown in Table 1. To determine which element is responsible for the directly binding of PPAR $\delta$, reporter assays were performed using serially truncated constructs driven by the Ski promoter. The response to PPAR $\delta$ was almost completely abolished on the deletion of sequences located between -958 and -851, which indicates that the element responsible for PPAR $\delta$ is located between -958 and -851 bp upstream of the rat Ski gene (Fig. 3A). As shown in Table 1 and Figure 3B, this region contains a putative DR1 element at positions -865 to -853 of the Ski promoter. To assess whether or not this PPRE mediates transcriptional activation by PPAR $\delta$, we introduced mutations into the Ski promoter construct. In the presence of the wild-type Ski-DR1 site, GW501516-mediated PPAR $\delta$ activation resulted in significant increase in transcriptional activity. However, mutations of the DR1 caused loss of promoter activation by the PPAR $\delta$ ligand (Fig. 3C). These results clearly demonstrate that this DR1 site mediates the PPAR $\delta$ binding and regulation to Ski promoter.

To determine whether or not PPAR $\delta$ binds directly to the Ski-DR1 site, we performed EMSA and ChIP. As expected, interaction of Ski-DR1 probe with the nuclear extract of fibroblasts yielded a DNA/protein band of mobility (Fig. 3D). This binding was sequence specific because no protein-DNA complex was observed between the nuclear extract and a mutated or cold Ski-DR1 probe, or in the presence of Ski-DR1 probe but without nuclear extract (Fig. 3D). Addition of antibody against PPAR $\delta$ to the reaction mixture resulted in further retarded migration of the radio labeled band (Fig. 3C), which confirmed the identity of the protein that interacts with the DNA as being PPAR $\delta$. And ChIP assay showed that in 
Fig. 3. Activation of $\operatorname{PPAR} \delta$ increases Ski promoter activity via a DR1 sequence. (A) Rat skin fibroblasts were transfected with deletion constructs of the Ski gene promoter and treated with $50 \mathrm{nmol} / \mathrm{L}$ GW501516 or DMSO for 24 hours. And luciferase assay was performed as described in methods. Values (mean \pm SD) from 4 to 6 independent transfections are expressed as fold induction relative to the control (pGL3 basic). NS: not significant. (B) Schematic representation of the Ski gene promoter. The potential PPAR response element (DR1 ${ }_{-865 \sim 853}$ ) was mutated by site-directed mutagenesis (underlined). (C) Cells were transfected with luciferase reporter plasmids driven by the Ski promoter $_{-958 \sim-19}$ contaning wild type $\mathrm{DR} 1_{-865 \sim-853}$ or mutated DR1 $1_{-865 \sim 853}$ region and treated with GW501516 or DMSA. Then luciferase activities were measured. ${ }^{*} P<0.05$, when comparing the two groups. (D) EMSA analysis of PPAR $\delta$ binding to the putative PPRE/ DR1. The nuclear extracts were prepared from fibroblasts and EMSA was performed

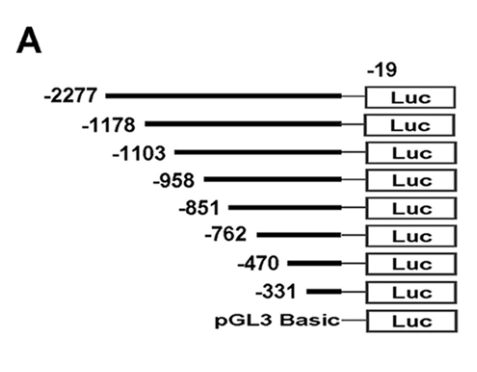

B

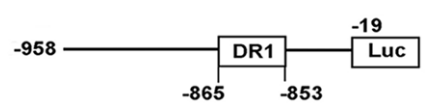

Ski DR1wt AGGTAAGGGGACA Ski DR1mutant AGGCGAGGTAACA

D

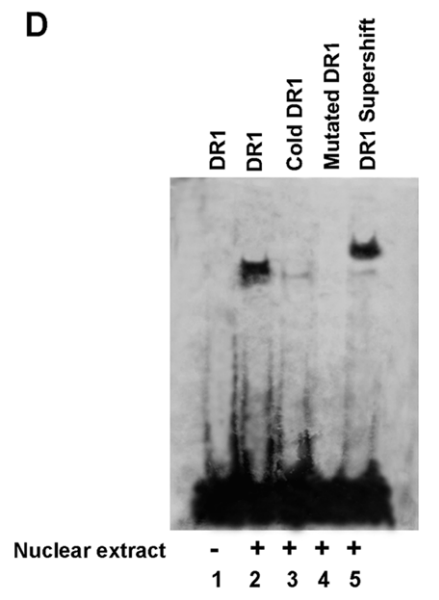

Luciferase activity (fold)

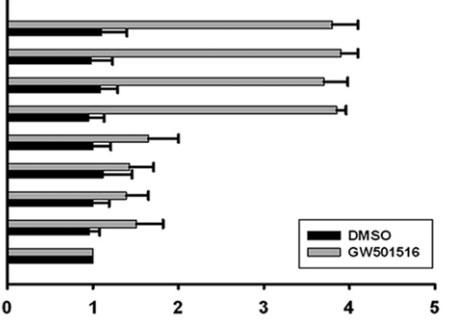

C

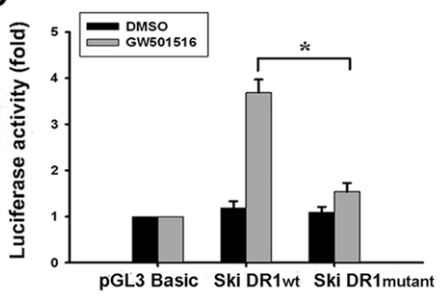

$\mathbf{E}$

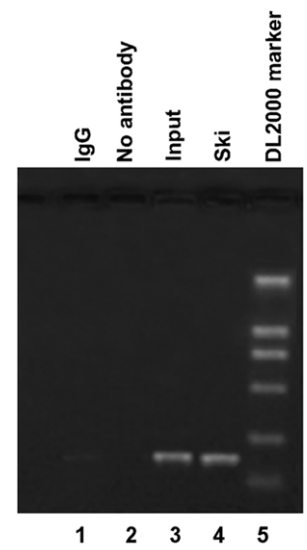

using end-labeled wild-type (lane 2) or mutated Ski-DR1 $1_{-865 \sim-853}$ probes (lane 4), or clod wild-type Ski-DR1 $1_{-865 \sim 853}$ probe (lane 3). Ski-DR1 $1_{-865 \sim 853}$ alone (without nuclear extract, lane 1) was served as negative control. Supershift experiment was performed with anti-PPAR $\delta$ antibody (lane 5). (E) ChIP assays were performed using chromatin isolated from fibroblasts treated with GW501516 for $24 \mathrm{~h}$. Rat IgG (lane 1) and chromatin without anti-PPAR $\delta$ antibody incubation (lane 2) were served as negative controls while the input (lane 3) was the positive control for the amplification of DR1 sequence in Ski promoter region (lane 4). Lane 5 is the DL2000 marker. Representative data from 3 experiments were shown.

the samples treated with GW501516, PPAR $\delta$ was found associated with the PCR-amplified region corresponding to the promoter region containing the putative Ski-DR1 site, whereas no reactivity was detected in the presence of IgG or without treatment with anti-PPAR $\delta$ antibody (Fig. 3E). These results further confirm the direct and specific binding of PPAR $\delta$ to the PPRE (DR1) identified in the Ski promoter region.

\section{PPAR $\delta$ activation-induced proliferation of fibroblasts largely depends on Ski}

Fibroblast proliferation is known to be one essential factor involved in skin wound healing. Accordingly, we examined whether or not PPAR $\delta$-regulated Ski expression affects the proliferation of fibroblast. Consistent with our previous report [11], Ski expression was successfully knockdown by pSuper-Ski-RNAi transfection in fibroblasts (Fig. 4A). And as shown in Figure 4B, GW501516 markedly accelerate the growth of fibroblast during the detected 72 hours. However, when the cells were pretreated with Ski RNAi the effect of GW501516 was significantly attenuated. This result indicates that Ski is a potential novel 
A

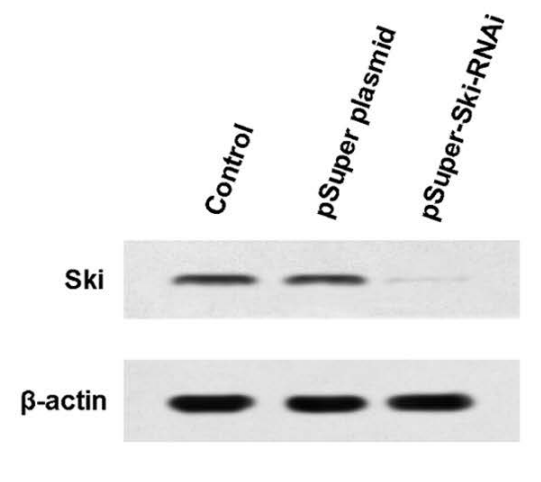

B

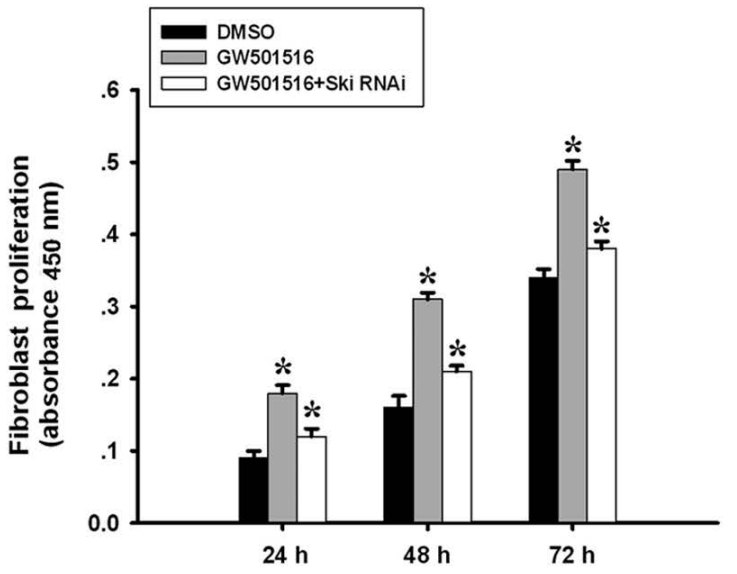

Fig. 4. Ski is involved in the PPAR $\delta$-induced proliferation of fibroblasts. Fibroblasts were treated with DMSO, or GW501516, or pSuper-c-Ski-RNAi followed by GW501516. (A) Western blot for Ski expression, which is to confirm the efficiency of Ski RNAi. (B) The proliferation of fibroblasts was assayed using a CCK-8 Kit with WST-8 dye method at $0 \mathrm{~h}, 24 \mathrm{~h}, 48 \mathrm{~h}$ and $72 \mathrm{~h}$ after DMSO or GW501516 treatment. The representative results are from 3 separate experiments, and the data are expressed as the mean \pm SD. * Indicates $P<0.05$ when compared with DMSO group at the different time point.

target gene for PPAR $\delta$, which largely mediates the PPAR $\delta$ activation-induced proliferation of fibroblasts.

PPARS induces Ski expression in vivo and promote rat skin wound healing in a Skidependent manner

Finally, to investigate whether PPAR $\delta$ can modulate Ski expression in vivo and whether this modulation is implicated in skin wound repair, we examined the level of Ski mRNA and protein in wounds treated with vehicle (DMSO) or GW501516 and observed the associated wound closure and re-epithelialisation in rat skin wound healing model. The results showed that the endogenous Ski mRNA and protein levels increased significantly at 6 days postwounding but decreased at 12 days and 18 days post-wounding in a time dependent manner. However, GW501516 administration could stimulate Ski expression in wounds at both mRNA level (Fig. 5A) and protein level (Fig. 5B), which was accompanied with promotion of the skin wound closure (Fig. 5C). Further histology analysis demonstrated that GW501516 treatment accelerated re-epithelialisation and granulation tissue generation (Fig. 5D). When compared with the DMSO treatment side, at 6 days post-wounding, the granulation tissue of GW501516-treated side proliferated significantly, with approximately covering the entire wound area by 12 days. In addition, creeping of the epithelium toward the centre of the wound was more rapid after administration of GW501516. On Day 18 post-wounding, continuous intact epithelialization and neoformative granulation tissue were observed in GW501516-treated side to closure the wounding while DMSO-treated side still presented defective epithelialization and unclosed wounding.

Being our recent study has verified pSuper-c-Ski-RNAi injection could successfully knockdown Ski expression in wound, accordingly, in the present study, we used this Ski RNAi to investigate whether GW501516-activated PPAR $\delta$ activity was associated with regulation of Ski by PPAR $\delta$. As expected, the beneficial effects of GW501516 on wound healing were found to be largely blocked when Ski expression was previously interfered (Fig. 5C and D). Therefore, these results confirm the induction of Ski expression by PPAR $\delta$ in vivo and suggest that PPAR $\delta$ promote rat skin wound healing in a Ski-dependent manner. 
A

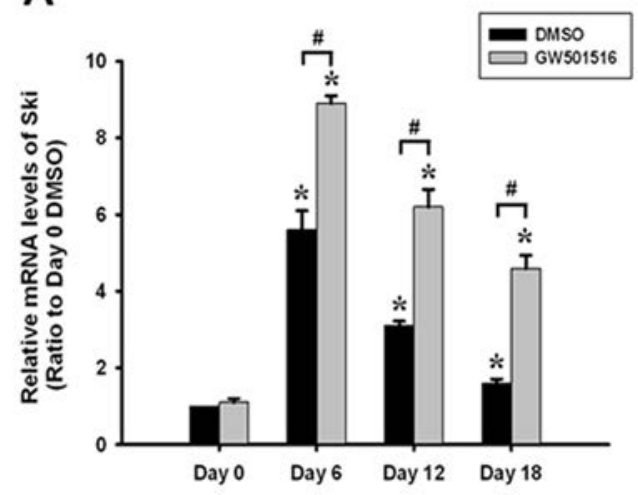

C
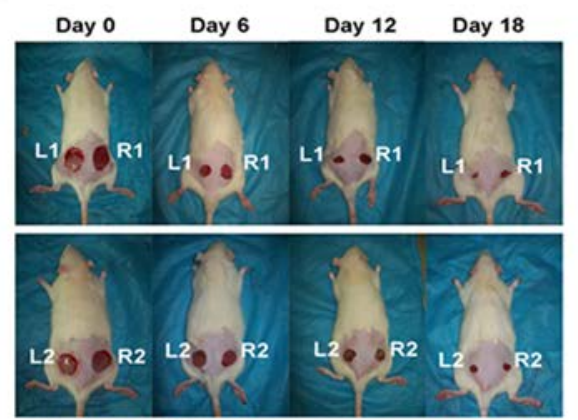

L1: GW501516 treatment

L2: GW501516 + Ski RNAi treatment

R1, R2: DMSO treatment
B

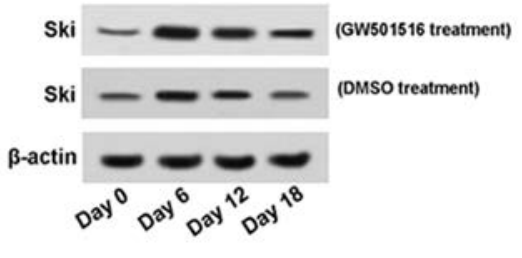

D

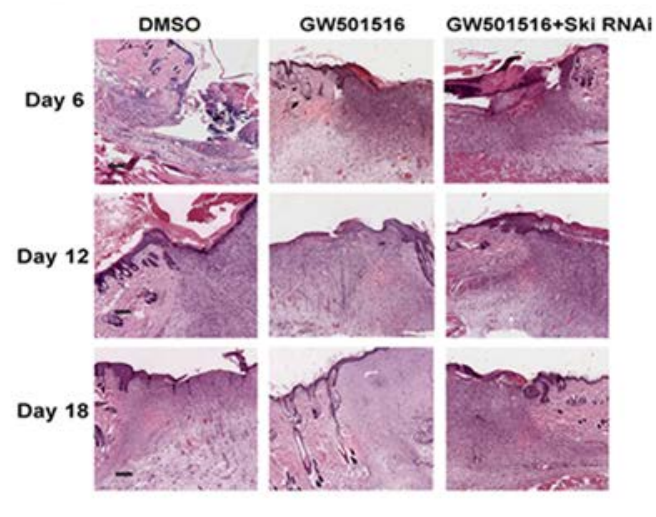

Fig. 5. PPAR $\delta$ promotes wound healing in a Ski-dependent manner. (A) Relative Ski mRNA expressions in wounds on day 0 , day 6, day 12 and day 18 post-wounding. (B) Western blot for Ski protein expressions in wounds on day 0 , day 6, day 12 and day 18 post-wounding. (C) Photographs of representative wounds in rats at $0,6,12$ and 18 days post-wounding. In each animal, the left-hand wound was injected weekly with 100 $\mu \mathrm{g}$ GW501516 or 100 pSuper-c-Ski-RNAi followed by GW501516, beginning immediately after wounding, while the right-hand wound served as a vehicle DMSO-treated control. (D) Histopathological characteristics of wound healing at 6,12 and 18 days post-wounding. Wound tissue sections $(6 \mathrm{~mm})$ were stained with haematoxylin and eosin (H\&E) for morphological assessment. Epithelial crawling and granulation tissue formation were presented. Scale bars $=0.2 \mathrm{~mm}$.

\section{Discussion}

Nuclear receptor PPAR $\delta$ has been reported to regulate the expression of multiple genes to elicit a wide spectrum of responses under different physiological and pathological conditions $[30,31]$. In skin trauma, activation of PPAR $\delta$ is found to efficiently promote wound healing [32-35], but very little is known about the actual effector genes that it regulates during this course. Here, we demonstrate that PPAR $\delta$ activation by its specific agonist GW501516 induces the expressions of Ski mRNA and protein in rat fibroblasts. Transfection experiments reveal that Ski expression is regulated by PPAR $\delta$ at the transcriptional level. Mutation of the DR1 site located in the Ski promoter region abolishes the PPAR $\delta$-induced Ski transcription, indicating that this site is a novel type of PPRE. Furthermore, along with upregulation of Ski, activation of PPAR $\delta$ stimulates the proliferation of fibroblasts in vitro 
and accelerates wound healing of rat in vivo, which suggests that these effects of PPAR $\delta$ in wound healing is largely mediated by its target gene Ski.

Skin wound repair is divided into three phases: inflammation, epithelialization and remodeling [36]. Keratinocytes, macrophages and dermal fibroblasts is critical for this repair process [37-39]. Previous studies have demonstrated that activation of PPAR $\delta$ in keratinocytes increased resistance of the keratinocytes to the apoptotic signals released during wounding, allowing faster re-epithelialisation [23, 35], and activation of PPAR $\delta$ in infiltrated macrophages attenuates the inflammatory response [31, 34, 40], which also promotes repair. In the present study, we found PPAR $\delta$ is also expressed in rat fibroblasts and its activation siginificantly accelerates the proliferation of fibroblasts along with upregulating the expression of Ski, another wound repair gene. This induction of Ski by PPAR $\delta$ occurs at the transcriptional level via binding of the PPAR $\delta$ to the PPRE located in the 5'-flanking region of the Ski gene. Although several potential PPRE are indicated by bioinformatics analysis, we identified DR1 as a cis-element in the promoter region of the Ski gene and demonstrated that it is responsible for PPAR $\delta$-induced upregulation of Ski. This DR1 sequence is "AGGTAAGGGGACA", containing a canonical DR1 motif separated by a guanine, which located at -865 -853 of rat Ski gene. The other three putative DR1 sites located at $-1264 \sim-1252,-816 \sim-804$ or $-377 \sim-365$ respectively are verified to be not involved in the PPAR $\delta$ binding and induction.

During the progression of skin wound repair, fibroblasts proliferate and invade lesions, modulate local inflammation, generate ECM to serve as a scaffold for other cells and possess cytoskeletal elements that facilitate contractions of healing wounds. Disorder of fibroblast proliferation would result in delayed wound healing. Our further investigation demonstrates that this binding of PPAR $\delta$ to Ski promoter is a functional activity which upregulates Ski expression to be responsible for PPAR $\delta$-induced fibroblasts proliferation in vitro and rat skin wound healing in vivo. And it provides evidence for the transcriptional regulation of the Ski gene in mammalian cells.

Ski is a co-repressor for transforming growth factor- $\beta$ (TGF- $\beta$ )/Smad signaling [5] and TGF- $\beta$ has been reported to play a dual role influencing tissue repair [41-44]. Our previous study indicated the essential role for Ski in mediating TGF- $\beta 1$-induced bi-directional effects on skin fibroblast proliferation through a feedback loop. Kim et al. found TGF$\beta 1$ is a molecular target for PPAR $\delta$ in vascular smooth muscle cells [45] while Tan et al. demonstrated that a cross-talk between TGF- $\beta$ and PPAR $\delta$ signaling in wound healing [46]. Hererin, although we have not investigated whether TGF- $\beta$ expression or activity is affected by the PPAR $\delta$-upregulated, on the basis of these findings and references, it might turn out that the interaction of PPAR $\delta$, TGF- $\beta$ and Ski assumes to be closely correlated to maintaining the homeostasis and dictating the outcome of wound tissues.

In addition, it should be noted that Ski is also found to be an oncogene involved in the progression of some carcinomas such as esophageal squamous cell carcinoma, melanoma and lung cancer [47-49] and PPAR $\delta$ is reported to either accelerate or suppress tumor growth [50-52]. Since wound healing closely resembles the phenotypic events that are observed during squamous cell carcinoma progression in many aspects [21], the cell and tissue specificity of the PPAR $\delta$ regulation on Ski needs to be detected. Furthermore, the safety and potential paradoxical effects of the application of exogenous PPAR $\delta$ agonist targeting Ski at wound sites should also be determined to avoid potential side effect of tumorigenesis in further investigation.

In summary, our findings in the present study indicate that Ski is a target gene for PPAR $\delta$, which to some extent mediates PPAR $\delta$ effect on skin wound healing. This has important implications not only for the understanding of the molecular mechanisms underlying the roles of PPAR $\delta$ in wound repair but also for the transcriptional regulation of the Ski gene. It also provides essential novel evidence to suggest that PPAR $\delta$ ligands may be used to effect transient activation of local Ski signaling and thus become a therapeutically relevant strategy for the treatment of skin wound. 
Li/Li/Zhang et al.: PPARS Upregulates Ski to Promote Wound Healing

\section{Acknowledgements}

We gratefully acknowledge Professor Zhong-Lu Liu and Mr. Nan Yang for handling the animals. This work was supported by the grants from National Natural Science Foundation of China (No. 81070229) and Natural Science Foundation Project of Chongqing Science and Technology Commission, China (No. CSTC 2009BB5139).

\section{Reference}

1 Coulombe PA: Wound epithelialization: accelerating the pace of discovery. J Invest Dermatol 2003;121:219230 .

2 Werner S, Grose R: Regulation of wound healing by growth factors and cytokines. Physiol Rev 2003;83:835870.

3 Li Y, Turck CM, Teumer JK, Stavnezer E: Unique sequence, ski, in Sloan-Kettering avian retroviruses with properties of a new cell-derived oncogene. J Virol 1986;57:1065-1072.

4 Deheuninck J, Luo K: Ski and SnoN, potent negative regulators of TGF-beta signaling. Cell Res 2009;19:4757.

5 Akiyoshi S, Inoue H, Hanai J, Kusanagi K, Nemoto N, Miyazono K, Kawabata M: c-Ski acts as a transcriptional co-repressor in transforming growth factor-beta signaling through interaction with smads. J Biol Chem 1999;274:35269-35277.

6 Bonnon C, Atanasoski S: c-Ski in health and disease. Cell Tissue Res 2012;347:51-64.

7 Baranek C, Dittrich M, Parthasarathy S, Bonnon CG, Britanova O, Lanshakov D, Boukhtouche F, Sommer JE, Colmenares C, Tarabykin V, Atanasoski S: Protooncogene Ski cooperates with the chromatin-remodeling factor Satb2 in specifying callosal neurons. Proc Natl Acad Sci U S A 2012;109:3546-3551.

8 Diaz M, Martel N, Fitzsimmons RL, Eriksson NA, Cowin G, Thomas G, Le Cao KA, Muscat GE, Leong GM: Ski overexpression in skeletal muscle modulates genetic programs that control susceptibility to diet-induced obesity and insulin signaling. Obesity (Silver Spring) 2012;DOI: oby2012101 [pii] 10.1038/oby.2012.101.

-9 Kiyono K, Suzuki HI, Morishita Y, Komuro A, Iwata C, Yashiro M, Hirakawa K, Kano MR, Miyazono K: c-Ski overexpression promotes tumor growth and angiogenesis through inhibition of transforming growth factor-beta signaling in diffuse-type gastric carcinoma. Cancer Sci 2009;100:1809-1816.

10 Li P, Liu P, Xiong RP, Chen XY, Zhao Y, Lu WP, Liu X, Ning YL, Yang N, Zhou YG: Ski, a modulator of wound healing and scar formation in the rat skin and rabbit ear. J Pathol 2011;223:659-671.

-11 Liu X, Li P, Liu P, Xiong R, Zhang E, Chen X, Gu D, Zhao Y, Wang Z, Zhou Y: The essential role for c-Ski in mediating TGF-beta1-induced bi-directional effects on skin fibroblast proliferation through a feedback loop. Biochem J 2008;409:289-297.

12 Liu X, Zhang E, Li P, Liu J, Zhou P, Gu DY, Chen X, Cheng T, Zhou Y: Expression and possible mechanism of cski, a novel tissue repair-related gene during normal and radiation-impaired wound healing. Wound Repair Regen 2006;14:162-171.

13 Novac N, Heinzel T: Nuclear receptors: overview and classification. Curr Drug Targets Inflamm Allergy 2004;3:335-346.

14 Evans RM: The steroid and thyroid hormone receptor superfamily. Science 1988;240:889-895.

15 Warnmark A, Treuter E, Wright AP, Gustafsson JA: Activation functions 1 and 2 of nuclear receptors: molecular strategies for transcriptional activation. Mol Endocrinol 2003;17:1901-1909.

16 Desvergne B, IJpenberg A, Devchand PR, Wahli W: The peroxisome proliferator-activated receptors at the cross-road of diet and hormonal signalling. J Steroid Biochem Mol Biol 1998;65:65-74.

17 Desvergne B, Wahli W: Peroxisome proliferator-activated receptors: nuclear control of metabolism. Endocr Rev 1999;20:649-688.

18 Kersten S, Desvergne B, Wahli W: Roles of PPARs in health and disease. Nature 2000;405:421-424. 
19 Lazennec G, Canaple L, Saugy D, Wahli W: Activation of peroxisome proliferator-activated receptors (PPARs) by their ligands and protein kinase A activators. Mol Endocrinol 2000;14:1962-1975.

-20 Tugwood JD, Issemann I, Anderson RG, Bundell KR, McPheat WL, Green S: The mouse peroxisome proliferator activated receptor recognizes a response element in the 5 ' flanking sequence of the rat acyl CoA oxidase gene. EMBO J 1992;11:433-439.

21 Tan NS, Michalik L, Di-Poi N, Desvergne B, Wahli W: Critical roles of the nuclear receptor PPARbeta (peroxisome-proliferator-activated receptor beta) in skin wound healing. Biochem Soc Trans 2004;32:97102.

-22 Tan NS, Michalik L, Desvergne B, Wahli W: Peroxisome proliferator-activated receptor-beta as a target for wound healing drugs. Expert Opin Ther Targets 2004;8:39-48.

23 Tan NS, Michalik L, Desvergne B, Wahli W: Peroxisome proliferator-activated receptor (PPAR)-beta as a target for wound healing drugs: what is possible? Am J Clin Dermatol 2003;4:523-530.

-24 Ham SA, Kim HJ, Kang ES, Eun SY, Kim GH, Park MH, Woo IS, Chang KC, Lee JH, Seo HG: PPARdelta promotes wound healing by up-regulating TGF-beta1-dependent or -independent expression of extracellular matrix proteins. J Cell Mol Med 2010;14:1747-1759.

25 Zargarova T, Kulakova O, Prassolov V, Zharmukhamedova T, Tsyganova V, Turobov V, Ivanov D, Parfenov M, Sudomoina M, Chernajovsky Y, Favorova O: Prevention of experimental autoimmune encephalomyelitis in DA rats by grafting primary skin fibroblasts engineered to express transforming growth factor-beta1. Clin Exp Immunol 2004;137:313-319.

26 Liu X, Liu JZ, Zhang E, Li P, Zhou P, Cheng TM, Zhou YG: Impaired wound healing after local soft x-ray irradiation in rat skin: time course study of pathology, proliferation, cell cycle, and apoptosis. J Trauma 2005;59:682-690.

27 Chao F, Gong W, Zheng Y, Li Y, Huang G, Gao M, Li J, Kuruba R, Gao X, Li S, He F: Upregulation of scavenger receptor class B type I expression by activation of FXR in hepatocyte. Atherosclerosis 2010;213:443-448.

-28 Takasu H, Sugita A, Uchiyama Y, Katagiri N, Okazaki M, Ogata E, Ikeda K: c-Fos protein as a target of antiosteoclastogenic action of vitamin D, and synthesis of new analogs. J Clin Invest 2006;116:528-535.

29 Li Y, Yin W, Wang X, Zhu W, Huang Y, Yan G: Cholera toxin induces malignant glioma cell differentiation via the PKA/CREB pathway. Proc Natl Acad Sci U S A 2007;104:13438-13443.

-30 Montagner A, Rando G, Degueurce G, Leuenberger N, Michalik L, Wahli W: New insights into the role of PPARs. Prostaglandins Leukot Essent Fatty Acids 2011;85:235-243.

-31 Kilgore KS, Billin AN: PPARbeta/delta ligands as modulators of the inflammatory response. Curr Opin Investig Drugs 2008;9:463-469.

32 Short B: Time (and PPAR beta/delta) heals all wounds. J Cell Biol 2009;184:767.

33 Wahli W: Peroxisome proliferator-activated receptors (PPARs): from metabolic control to epidermal wound healing. Swiss Med Wkly 2002;132:83-91.

34 Chong HC, Tan MJ, Philippe V, Tan SH, Tan CK, Ku CW, Goh YY, Wahli W, Michalik L, Tan NS: Regulation of epithelial-mesenchymal IL-1 signaling by PPARbeta/delta is essential for skin homeostasis and wound healing. J Cell Biol 2009;184:817-831.

35 Tan NS, Michalik L, Noy N, Yasmin R, Pacot C, Heim M, Fluhmann B, Desvergne B, Wahli W: Critical roles of PPAR beta/delta in keratinocyte response to inflammation. Genes Dev 2001;15:3263-3277.

-36 Singer AJ, Clark RA: Cutaneous wound healing. N Engl J Med 1999;341:738-746.

-37 Zajicek R, Mandys V, Mestak O, Sevcik J, Konigova R, Matouskova E: Human Keratinocyte Growth and Differentiation on Acellular Porcine Dermal Matrix in relation to Wound Healing Potential. ScientificWorldJournal 2012;2012:727352.

-38 Miao M, Niu Y, Xie T, Yuan B, Qing C, Lu S: Diabetes-impaired wound healing and altered macrophage activation: a possible pathophysiologic correlation. Wound Repair Regen 2012;20:203-213.

-39 Parsonage G, Filer AD, Haworth O, Nash GB, Rainger GE, Salmon M, Buckley CD: A stromal address code defined by fibroblasts. Trends Immunol 2005;26:150-156.

40 Tan NS, Michalik L, Di-Poi N, Ng CY, Mermod N, Roberts AB, Desvergne B, Wahli W: Essential role of Smad3 in the inhibition of inflammation-induced PPARbeta/delta expression. EMBO J 2004;23:4211-4221.

41 Mustoe TA, Pierce GF, Thomason A, Gramates P, Sporn MB, Deuel TF: Accelerated healing of incisional wounds in rats induced by transforming growth factor-beta. Science 1987;237:1333-1336. 
-42 Puolakkainen PA, Reed MJ, Gombotz WR, Twardzik DR, Abrass IB, Sage HE: Acceleration of wound healing in aged rats by topical application of transforming growth factor-beta(1). Wound Repair Regen 1995;3:330-339.

43 Koch RM, Roche NS, Parks WT, Ashcroft GS, Letterio JJ, Roberts AB: Incisional wound healing in transforming growth factor-beta1 null mice. Wound Repair Regen 2000;8:179-191.

44 Crowe MJ, Doetschman T, Greenhalgh DG: Delayed wound healing in immunodeficient TGF-beta 1 knockout mice. J Invest Dermatol 2000;115:3-11.

-45 Kim HJ, Ham SA, Kim SU, Hwang JY, Kim JH, Chang KC, Yabe-Nishimura C, Seo HG: Transforming growth factor-beta1 is a molecular target for the peroxisome proliferator-activated receptor delta. Circ Res 2008;102:193-200.

46 Tan NS, Michalik L, Desvergne B, Wahli W: Genetic- or transforming growth factor-beta 1-induced changes in epidermal peroxisome proliferator-activated receptor beta/delta expression dictate wound repair kinetics. J Biol Chem 2005;280:18163-18170.

47 Fukuchi M, Nakajima M, Fukai Y, Miyazaki T, Masuda N, Sohda M, Manda R, Tsukada K, Kato H, Kuwano H: Increased expression of c-Ski as a co-repressor in transforming growth factor-beta signaling correlates with progression of esophageal squamous cell carcinoma. Int J Cancer 2004;108:818-824.

-48 Javelaud D, van Kempen L, Alexaki VI, Le Scolan E, Luo K, Mauviel A: Efficient TGF-beta/SMAD signaling in human melanoma cells associated with high c-SKI/SnoN expression. Mol Cancer 2011;10:2.

49 Carbo N, Costelli P, Busquets S, Lopez-Soriano J, Lopez-Soriano FJ, Baccino FM, Argiles JM: Effect of c-ski overexpression on the development of cachexia in mice bearing the Lewis lung carcinoma. Int J Mol Med 2004;14:719-723.

50 Jaeckel EC, Raja S, Tan J, Das SK, Dey SK, Girod DA, Tsue TT, Sanford TR: Correlation of expression of cyclooxygenase-2, vascular endothelial growth factor, and peroxisome proliferator-activated receptor delta with head and neck squamous cell carcinoma. Arch Otolaryngol Head Neck Surg 2001;127:1253-1259.

51 Tong BJ, Tan J, Tajeda L, Das SK, Chapman JA, DuBois RN, Dey SK: Heightened expression of cyclooxygenase2 and peroxisome proliferator-activated receptor-delta in human endometrial adenocarcinoma. Neoplasia 2000;2:483-490.

52 Peters JM, Lee SS, Li W, Ward JM, Gavrilova O, Everett C, Reitman ML, Hudson LD, Gonzalez FJ: Growth, adipose, brain, and skin alterations resulting from targeted disruption of the mouse peroxisome proliferator-activated receptor beta(delta). Mol Cell Biol 2000;20:5119-5128. 